\title{
Synthesis of periclinal chimera in cassava
}

\author{
N.M.A. Nassar and N. Bomfim \\ Departamento de Genética e Morfologia, Universidade de Brasília, \\ Brasília, DF, Brasil
}

Corresponding author: N.M.A. Nassar

E-mail: nagnassa@rudah.com.br

Genet. Mol. Res. 12 (1): 610-617 (2013)

Received October 29, 2012

Accepted December 18, 2012

Published February 27, 2012

DOI http://dx.doi.org/10.4238/2013.February.27.10

\begin{abstract}
We provide the first report on the synthesis of a very productive interspecific periclinal chimera of cassava, with large and edible roots. The epidermal tissue of the chimera was formed by the cultivated species Manihot esculenta (E), and the subepidermis and internal tissue were formed by the wild species, Manihot fortalezensis (F). We used cytogenetics and morphological analyses to determine the origins of all tissues. These results may offer potential for the development of new lines for crop improvement based on the use of chimera composed of different combinations of wild species and cultivars.
\end{abstract}

Key words: Periclinal chimera; Manihot; Grafting; Edible roots 


\section{INTRODUCTION}

Cassava is the main food source for more than 800 million people in the tropics and sub-tropics (FAO, 2009). Over the last fifty years, crop improvement programs have mainly concentrated on simple clonal selection and intervarietal hybridization (Nassar and Ortiz, 2008). Interspecific hybridization studies aiming to incorporate desirable traits from wild species into cultivars can be particularly difficult due to strong interspecific barriers and the need to conduct several backcrosses, which can take several decades or longer (Nassar and Ortiz, 2010). Some authors have referred to importance of chimeras (Burge et al., 2002; Nassar, 2003,2004 ), others proposed using chimeras to combine potentially useful traits of wild populations and cultivars (Goffreda et al., 1990; Burge et al., 2002). However, no experimental trial has yet been attempted to improve economic characters using this technique. We here present results of the synthesis of periclinal chimera of the wild Manihot species, M. fortalezensis, and the cultivated species, cassava, M. esculenta.

Plant chimeras have been found to occur sporadically in nature, while others have been artificially synthesized between different species (Marcotrigiano and Gouin, 1984; Kaddoura and Mantell, 1991; Chen et al., 2006; Wang et al., 2011), but none have yet been shown to result in improved economic characters. Instead, previous studies of plant chimeras have aimed to examine their ontogeny and pure botanical aspects.

Attempts to produce chimeras were previously accomplished by tissue culture; however, very few survive to produce mature plants or are capable of establishing a new chimera line (Kaddoura and Mantell, 1991; Chen et al., 2006).

Sporadic interspecific chimeras have commonly been shown to arise from adventitious shoot graft union formation of the scion and rootstock (e.g., Stewart et al., 1972; Burge et al., 2002; Zhou et al., 2002; Chen et al., 2006; Deng et al., 2007). Although no direct economic value of these chimera was determined in previous studies, these researchers foresaw the future potential of synthesizing chimeras for this purpose.

In the present study, we synthesized, for the first time, an interspecific periclinal chimera of two Manihot species that differ in chromosome number and ploidy level. One of these, UnB 201, is a cultivar known for its good nutrition quality and taste, but has low productivity (Nassar et al., 2011a). It is particularly susceptible to borer infestation and is highly vulnerable to drought. The second species, $M$. fortalezensis, is well adapted to drought, tolerant to borers and is known for its deep roots that can capture water from deep underground (Nassar et al., 2011b).

\section{MATERIAL AND METHODS}

\section{Plant material}

Two Manihot species were used in this study: M. fortalezensis (F) and the cultivar UnB 201 of the cultivated species, M. esculenta (cassava) (E). Both species were maintained in the living collection of Universidade de Brasília (UnB).

M. fortalezensis is an erect shrub ca. $4 \mathrm{~m}$, that is woody with deep fibrous roots and native to the savanna forest of Ceará, Brazil, where drought is predominant (Nassar et al., 2011b). The cassava cultivar UnB 201 is a low shrub 1-1.50 $\mathrm{m}$ in height. It was selected from 
indigenous cassava with high protein and carotene contents. It has excellent palatability, high betacarotene and protein contents, and produces edible roots of $2-3 \mathrm{~kg} / \mathrm{plant}$ by the age of one year (Nassar et al., 2007, 2011a).

\section{Chimera synthesis}

Stalks of M. fortalezensis were whip grafted onto 40 cassava cultivars UnB 201, which served as rootstocks. One year later, the fully grown scion was removed by making a cut parallel to the graft union, leaving only $5 \mathrm{~mm}$ of scion tissue. The graft unions and remaining graft tissue were covered by cotton to which 4 drops of $0.01 \% \alpha$-naphthaleneacetic acid solution were added. Shoot buds forming from the decapitated ends were removed.

By the end of the growing season, shoots that exhibited the chimera form and shape were propagated vegetatively. Eighteen plants were raised and their flowering buds were examined cytogenetically for meiosis. Fruits, leaves, and roots were all examined morphologically. Germinated roots of rooted cuttings were examined mitotically. Furthermore, the root production of the chimera was compared to that of the cassava parent.

\section{Cytogenetic analysis}

Male buds were collected, fixed in Carnoy's solution, preserved in 70\% ethanol, and smeared and stained with $1 \%$ acetocarmine.

Root tips were collected from germinating chimera cuttings, pre-treated with $0.25 \%$ colchicine in distilled water for $1 \mathrm{~h}$, fixed in Carnoy's solution, preserved in 70\% ethanol, hydrolyzed in $1 \mathrm{~N} \mathrm{HCl}$ for $10 \mathrm{~min}$ and smeared and stained with $1 \%$ acetocarmine.

\section{Morphological examination}

Morphological characters of the 18 raised plants were examined for leaf shape and root and fruit characteristics, and these traits were compared to those of parents that were raised with chimera plants.

\section{RESULTS}

Two phenotypically similar chimera plants (Table 1) were obtained from graft cutting, which represents a frequency of $5 \%$ chimera induction $(2 / 40)$. These plants were reproduced by cuttings, and a total of 18 plants were grown for one year.

Identification of the chimera plants was possible based on leaf morphology and fruit shape. The chimera leaves were notably different in shape and form from the two parent species (Figure 1A and B). The chimera fruit exhibited a winged form, in spite of being carried on a stalk of M. fortalezensis, whose fruit is normally spheric (Figure 1B). Because the outer layer of fruit normally comes off of the outer layer (LI) (Goffreda et al., 1990; Zhou et al., 2002), it was concluded that the chimera was formed in the epidermis of the cassava, M. esculenta (E). 
Periclinal chimera in cassava

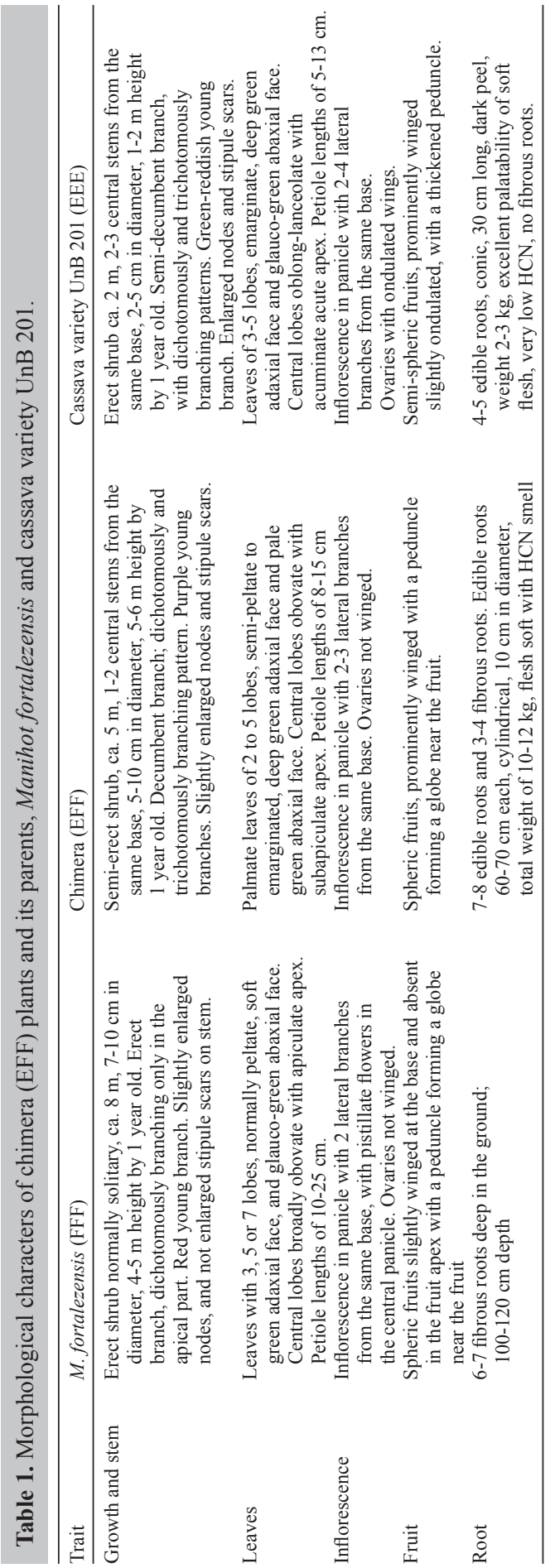

Genetics and Molecular Research 12 (1): 610-617 (2013) 


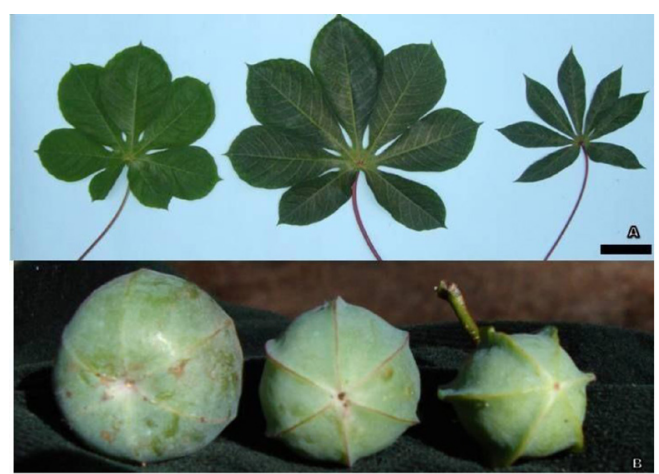

Figure 1. Morphological characters of chimera (EFF) compared to parents. A. Leaves: Manihot fortalezensis (left), chimera (center), cassava cultivar UnB 201 (right). B. Fruits: M. fortalezensis (left), chimera (center), cassava cultivar UnB 201 (right). Bar $=10 \mathrm{~cm}$.

The meiotic investigation of the chimera flowering bud revealed that the chimera chromosome number was $2 \mathrm{n}=54$, which is the same as that of $M$. fortalezensis (Figure 2A), indicating that the formation of LII layer of the chimera was from M. fortalezensis (Figure 2B). Root tip investigation of the two chimera plants also revealed a chromosome number of $2 n=54$. Since the roots normally originate from the inner tissue layer of pericycle, this demonstrated that the LIII was composed from $M$. fortalezensis, so that the final constitution of the chimera could be deduced as EFF.
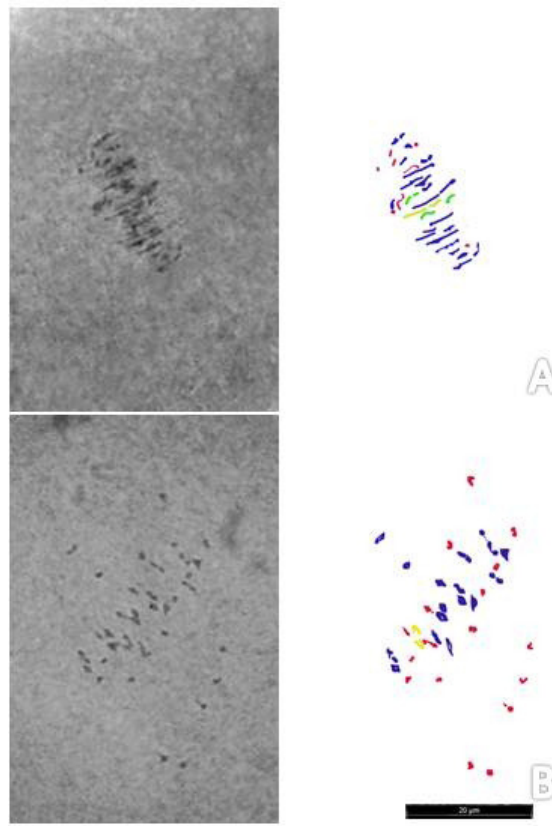

Figure 2. Meiotic metaphase I showing chromosome number. A. Manihot fortalezensis (FFF), 2n = 54, 23 bivalentes ( 20 in blue and 3 pairs recently separated: 2 in green and 1 in yellow). B. Cassava chimera (EFF), $2 \mathrm{n}=$ 54,17 bivalents (16 in blue an 1 recently separated in yellow), 17 univalents (red), 1 trivalent (blue)". 
After 1 year, propagated chimera plants showed extremely vigorous growth (almost 3 -fold) compared to that of their parents (Figure 3), and larger stem diameters relative to the cassava parent.

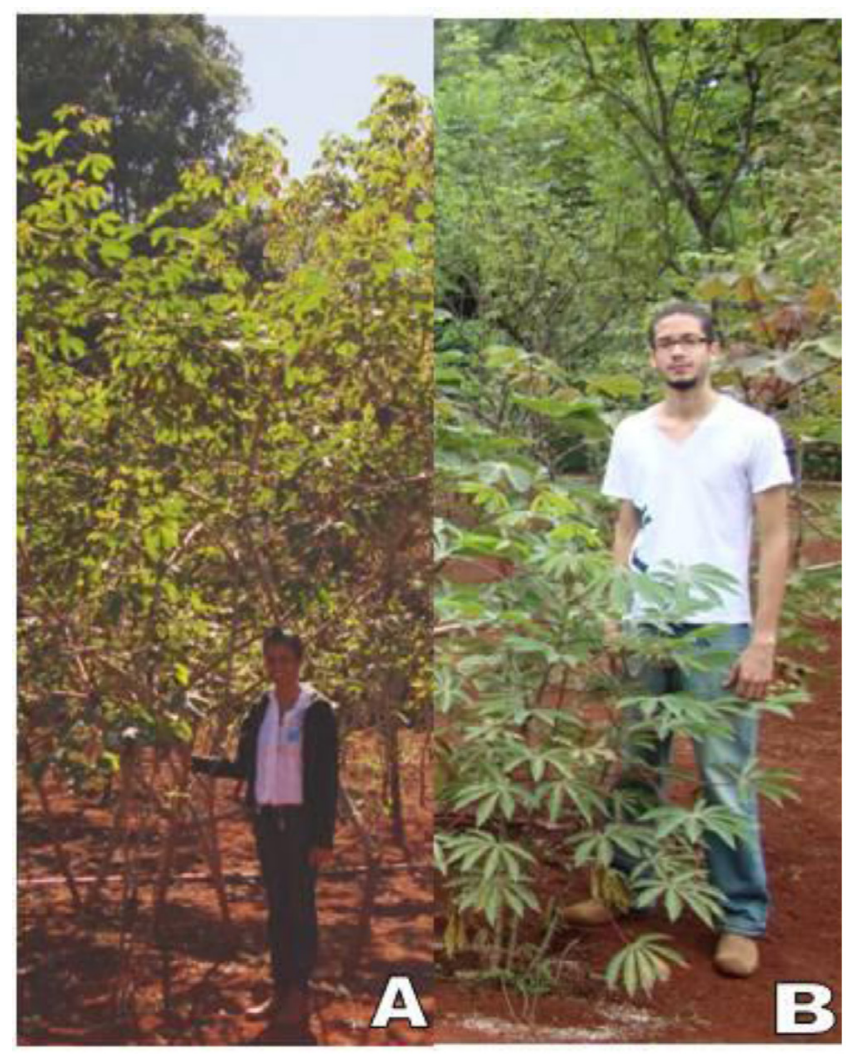

Figure 3. Chimera (EFF) vigorous growth compared to parent. A. Chimera. B. Cassava cultivar UnB 201.

\section{DISCUSSION}

The most interesting observation of the chimera formation was the development of extremely large edible roots compared to those of cassava. Root weight reached $10-12 \mathrm{~kg}$ in all plants by the age of 1 year, compared to weights of $2-3 \mathrm{~kg}$ in cassava plants of this age. The chimera therefore had a 5-fold increase in productivity. In contrast, $M$. fortalezensis does not form edible roots, but instead forms fibrous roots. In addition to the huge edible root formation, the chimera plants acquired deep fibrous roots as well; an indication of good tolerance to drought since these roots would allow for efficient capture of deep underground water. Since plant chimeras are a mosaic of genetically different cells in the short apical meristem, interactions between them in the same tissue may result in modified characters. Recent studies have suggested that the transfer of RNA, and even DNA, to adjacent cells in grafts induces epigenetic effects (Stegemann and Bock, 2009). 
The difference in chromosome number observed during both meiosis and mitosis was used to detect the chimeral constitution and revealed the most interesting feature of this graft chimera; the harmonious coexistence of genetically and chromosomally distinct tissues. In particular, this combination resulted in the production of a plant characterized by vigorous growth and a huge edible root. These characteristics should certainly favor the use of this chimera for breeding in the future. Furthermore, because the edible root of cassava is the main food source for poorer human populations in the tropics, the synthesis of this highly productive chimera may lead to a new line of research adopting the chimera technique for this crop's improvement. Varying the combination of wild species and cassava used, a large diversity of chimeras can be generated for different purposes.

In particular, chimera synthesis offers practical advantages for producing disease- or insect-resistant plants because the outer layer from a resistant species can be expressed in the inside layer of the synthesized cassava. Together, this technique may result in the development of a new resistant, drought-tolerant and productive cultivar within a short period of only 1 or 2 years.

\section{ACKNOWLEDGMENTS}

Research supported by the National Council for Scientific Development (CNPq) to N.M.A. Nassar, and a scholarship of the Foundation of Qualifying Graduate (CAPES) to N. Bomfim. The living collection of cassava wild species was established at Universidade de Brasília with support of the International Development Research Center of Canada (IDRC).

\section{REFERENCES}

Burge GK, Morgan ER and Seelye JF (2002). Opportunities for synthetic polant chimeral breeding: Past and future. Plant Cell Tissue Organ Cult. 70: 13-21.

Chen LP, Ge YM and Zhu XY (2006). Artificial synthesis of interspecific chimeras between tuber mustard (Brassica juncea) and cabbage (Brassica oleracea) and cytological analysis. Plant Cell Rep. 25: 907-913.

Deng MZD, Qin C, Chen C, Zhang H, et al. (2007). Characterization of a new natural periclinal navel-satsuma Chimera of Citrus: 'Zaohong' Navel Orange. J. Amer. Soc. Hort. Sci. 132: 374-380.

FAO (2009). Production Yearbook. Food and Agriculture Organization, Rome.

Goffreda JC, Szymkowiak EJ, Sussex BIM and Mutschler MA (1990). Chimeric tomato plants show that aphid resistance and triacylglucose production are epidermal autonomous characters. Plant Cell 2: 643-649.

Kaddoura RL and Mantell SH (1991). Synthesis and characterization of Nicotiana-Solanum graft chimeras. Ann. Bot. 68: 547-556.

Marcotrigiano M and Gouin FR (1984). Experimentally synthesized plant chimeras. 2. A comparison of in vitro and in vivo techniques for the production of interspecific Nicotiana chimeras. Ann. Bot. 54: 513-521.

Nassar N (2003). Fertility and chimera induction in cassava interspecific hybrids. Gene Conserve 2: 117-123.

Nassar N (2004). Polyploidy, chimera and fertility of interspecific cassava (Manihot esculenta Crantz) hybrids. Indian J. Genet. Plant Breed. 64: 132-133.

Nassar N and Ortiz R (2008). Cassava genetic resources: manipulation for crop improvement. Plant Breed. Rev. 31: 247275.

Nassar N and Ortiz R (2010). Breeding cassava to feed the poor. Sci. Am. 302: 78-82, 84.

Nassar N, Vizzotto CS, Schwartz CA and Pires OR Jr (2007). Cassava diversity in Brazil: the case of carotenoid-rich landraces. Genet. Mol. Res. 6: 116-121.

Nassar N, Bomfim NN, Elsayed AY and Freitas CS (2011a). Interesting cassava cultivars - UnB 201. Gene Conserve 10: 183-185.

Nassar N, Ribeiro DG, Bomfim NN and Gomes PTC (2011b). Manihot fortalezensis Nassar, Ribeiro, Bomfim et Gomes a new species of Manihot from Ceará, Brasil. Genet. Res. Crop Evol. 58: 831-835. 
Stegemann S and Bock R (2009). Exchange of genetic material between cells in plant tissue grafts. Science 324: 649-651. Stewart RN, Meyer FG and Dermen H (1972). Camellia + 'Daisy Eagleson', a graft chimera of Camellia sasanqua and C. japonica. Am. J. Bot. 59: 515-524.

Wang Y, Cheng Q, Zhu XY and Chen LP (2011). Studies on reproductive characteristics of an interspecific chimera between Brassica juncea and Brassica oleracea. Plant Cell Tissue Organ Cult. 104: 209-215.

Zhou J, Hirata Y, Nou IS, Shiotani H, et al. (2002). Interactions between different genotypic tissues in citrus graft chimeras. Euphytica 126: 355-364. 